\title{
Research Structure, and Quality of Academic Research in the Public Universities of the Republic of South Sudan
}

\author{
Aquila Hakim M. Jongroor \\ School of Public Health, Texila American University, South America, Guyana
}

\begin{abstract}
The purpose of the research is to evaluate the quality of academic research in public universities in the Republic of South Sudan with the objectives of establishing the relationship between research structure and quality of academic research. Descriptive and cross-sectional designs using both qualitative and quantitative techniques. The study was carried out in the five Universities. Both random and purposive sampling methods were used to identify 23 heads of departments, 65 teaching staff, and 205 dissertations reviewed with an average response rate of $91 \%$. Three tools were deployed to collect both qualitative and quantitative data. These include interview guide, observation checklist, and questionnaire. Participants consented before they participated in the study, and approvals were sought at the different levels. Utilized computation of research aggregates using the SPSS V 2. Descriptive statistical analysis was used for demographic information, and correlation analysis was used to determine relationships between variables and factors that may predict the quality of academic research. There is a positive correlation between independents variables (research procedure $r=$ 0.672 , structure $r=0.698$, format $r=0.8311$ with $p<0.01$ ). This implies that academic research structure contributes to good academic research. In conclusion, the structure of the academic research is not consistent between the five public universities in South Sudan, between the faculties and departments of the same public university. Academic research structure is positively correlated with the quality of the academic research in public universities of the Republic of South Sudan. There is consistency in the general structure of the academic research.
\end{abstract}

Keywords: Academic research, Structure, Quality.

\section{Introduction}

The purpose of the research is to evaluate the quality of academic research in public universities in the Republic of South Sudan with the objectives of establishing a relationship between academic research structure and quality of academic research. The academicians and scholars did not agree on a way of doing academic research because of the diversity and complexity of faculties and departments in higher learning institutions globally [1]. This resulted in a shortage of competent and committed researchers to foster research and development efforts. Public health and medical care policies, guidelines, procedures are based on the research findings. This is attributed to the lack of systematic introduction of undergraduates to research [2].

Failure of higher learning institutions to produce motivated and competent graduates or undergraduates will result in a lack of evidencebased decisions that will lead to more suffering and deaths [3].

The world is already in a dire situation from emerging and re-emerging infectious diseases (COVID-19) coupled with environmental impact such as threats posed by global warming. By creating an ever-expanding new knowledge base and new ideas, universities provide the best education to researchers, entrepreneurs, businessmen, and leaders of the future. 
However, many universities in emerging economies and the Middle East do not provide quality education to students for top industries to recruit them in the future [4]. Subsequently, not only do the students' prospect of getting employment in the best industries reduced, but the effect is felt in the economy and the development of a country. Over the last decade, tertiary education and research have not been made a priority in the way that they should have been in the United Arab Emirates (UAE) [5].

The research contributes to economic growth and development positively. Over 50\% of the countries are far from achieving Sustainable Development Goals. Countries with competent, innovative, and committed researchers have a higher life expectancy. Healthier workers are more productive hence increasing gross domestic product (GDP) [6].

The purpose of the research is to evaluate the quality of academic research in public universities in the Republic of South Sudan. The objectives of this research are (1) to evaluate academic research structure consistency in the public universities of the Republic of South Sudan and (2) to establish the relationship between academic research structure and quality of the academic research in the public universities of the Republic of South Sudan.

Hence the research questions are (1) what is the relation between academic research structure and quality of academic research in the public universities of the Republic of South Sudan? And (2) what is the relationship between academic research structure and quality of academic research in the public universities of the Republic of South Sudan?

With hypothesis "there is no relationship between research structure and quality of the academic research in the public universities of the Republic of South Sudan".

\section{Methods and Materials}

The research adopted descriptive and crosssectional designs using both qualitative and quantitative techniques to examine the relationship between academic research structure and quality of academic research in South Sudan's public universities. The descriptive research design was chosen because of its ability to provide great depth of responses and consequently results in a better understanding of the academic research quality in public universities of South Sudan as it exists [7].

The study population comprised of the head of departments and research committees, dean of faculties, teaching assistants, and lecturers [8].

The Sample size was redefined after the tool were tested. It was found out that is not easy to find the head of the universities and the dean of faculties. The oversample size is 225 participants and objects. A Total of 25, 75, and 125 head of departments or Deans of faculties, teaching staff (Lecturers, teaching assistants, etc.) and 225 dissertations respectively were targeted.

The researcher used both qualitative and quantitative data collection methods and obtained qualitative and quantitative data [9].

The data were collected using both quantitative and qualitative data collection instruments, which include questionnaires, interview guide, and observation checklist. Questionnaires and interview guides were administered to the dean of faculties, head of departments and lecturers, and teaching assistants [10]. Observation checklists were used to review dissertations, research policies, and guidelines. Summate scale was used to assess the extent to which respondents agreed or disagreed with statements related to the study variables [11].

An Introduction letter was obtained from Texila American University, and permission was sought from the university of juba, Rumbek University, Upper university, university of Bhar El Gazal, and Dr. John Garang University. Before a respondent provides information, they were given an opportunity to participate in the research on their will by providing an informed consent $[12,13]$. 
To ensure validity and reliability, the data collection tools were pre-tested to assess the language, clarity, and ability to solicit information needed. In addition, the instruments were also assessed for acceptability in terms of length and response of the respondents [14].

The qualitative data was categorized based on thematic categories derived from the study objectives. It consists of responses and suggestions from key informants.

Analysis of quantitative data utilized computation of research aggregates using the Statistical Package of (SPSS V 21). Descriptive statistical analysis was used for demographic information. Correlation analysis was used to determine relationships between variables and factors that may predict the quality of academic research in South Sudan. The regression analysis is the best because the researcher is interested in finding out if the independent variables will predict the dependent variable on the basis of continuous and/or categorical dependent variables; to rank the relative importance of independents; to assess interaction effects and understand the impact of covariate control variables $[15,16]$.

All key variables in this study were measured with a 5-point multi-item Likert scale. The results obtained through the questionnaire were analyzed through Statistical Package of Social Sciences (SPSS) version 21.0. Regression and factor analysis test helped in a proper understanding of major factors influencing the relationship between the independents and dependent variables.

\section{Results}

The research procedure is positively correlated with research structure $(r=0.777 \mathrm{p}<$ 0.01 ), and research structure is positively correlated with quality of academic research $(\mathrm{r}=$ $0.698, \mathrm{p}<0.01)$. This denotes that research procedures relate to the quality of academic research in public universities in South Sudan.

\section{Preliminary Pages}

The significant variations are seen in the contents and order under the main sections of the academic research in South Sudan Public Universities. This is in line with Onen findings.

The most common contents observed under preliminary pages are acknowledgement $96 \%$, dedication $91 \%$, title page $90 \%$, abstract $90 \%$, declaration $86 \%$, resolution $68 \%$, abbreviations $66 \%$, table of content $63 \%$, list of tables $56 \%$, and list of figures $44 \%$ Table 1.

Table 1. Distribution of Preliminary Pages availability and their Order

\begin{tabular}{|l|l|l|l|l|l|}
\hline Preliminary pages & Frequency & $\begin{array}{l}\text { Content } \\
\text { Order }\end{array}$ & Percent & $\begin{array}{l}\text { 2nd Content } \\
\text { order }\end{array}$ & Percent \\
\hline Acknowledgement & $96 \%$ & Third & $50 \%$ & Fourth & $24 \%$ \\
\hline Dedication & $91 \%$ & Second & $48 \%$ & Third & $30 \%$ \\
\hline Tile Page & $90 \%$ & Zero & $99 \%$ & & \\
\hline Abstract or Summary & $90 \%$ & Fourth & $44 \%$ & Fifth & $12 \%$ \\
\hline Declaration & $86 \%$ & First & $69 \%$ & Not there & $14 \%$ \\
\hline Resolution & $68 \%$ & Zero & $36 \%$ & Not there & $33 \%$ \\
\hline Abbreviations and Acronymns & $66 \%$ & Not there & $35 \%$ & Fifth & $18 \%$ \\
\hline Table of Content & $63 \%$ & Not there & $36 \%$ & Fifth & $15 \%$ \\
\hline List of Tables & $56 \%$ & Not there & $44 \%$ & Fifth & $21 \%$ \\
\hline List of Figures & $44 \%$ & Not there & $56 \%$ & Sixth & $15 \%$ \\
\hline List of Diagrams & $7 \%$ & Not there & $92 \%$ & Eighth & $3 \%$ \\
\hline Copy Right & $5 \%$ & Not there & $95 \%$ & & \\
\hline Definition of Key Terms & $3 \%$ & Not there & $97 \%$ & Sixth & $3 \%$ \\
\hline
\end{tabular}




\begin{tabular}{|l|l|l|l|l|l|} 
Other subheadings & $3 \%$ & Not there & $87 \%$ & & \\
\hline List of Equations & $1 \%$ & Not there & $99 \%$ & & \\
\hline
\end{tabular}

The order of preliminary pages contents was also observed using the observation checklist. Only title page, acknowledgement, and declaration emerged with page number zero (99\%), one (69\%), and three (50\%), respectively.

There is a significant variation of subheadings under chapter two based on the review of dissertations written by students in South Sudan's Public Universities. At least $77 \%$ of the dissertations reviewed had an introduction as the first subheading under chapter two. The study found that the contents of chapter two are as follow; constructs, variables, objectives, theoretical framework, conception framework, empirical, and summary/Conclusion of the literature review.

\section{Factor Structure Analysis}

Academic research preliminary pages explained the largest part of the total variance with an Eigenvalue of 2.192, Which amounts to $25.80 \%$ of the total variance. Academic research Structure explained the second largest part of the total variance with an Eigenvalue of 2.178 this amounts to $23.31 \%$ of the total variance, and finally, academic research appendixes explained the third variance with an Eigenvalue of 2.117 this amount to $20.21 \%$ of the total variance. The three components of the academic research structure contribute $69.3 \%$ cumulative variance Table 2.

Table 2. Factor Structure: Academic Research Structure

\begin{tabular}{|l|l|l|l|}
\hline Factors & \multicolumn{2}{l|}{ Components } & \multicolumn{2}{l|}{$\begin{array}{l}\text { Preliminary } \\
\text { Pages }\end{array}$} & Structure & Appendix \\
\hline $\begin{array}{l}\text { Staff and students are aware of the academic } \\
\text { research structure of this university (3) }\end{array}$ & .931 & & \\
\hline $\begin{array}{l}\text { The research structure is being used consistently to } \\
\text { the best of my knowledge (7) }\end{array}$ & .868 & & \\
\hline $\begin{array}{l}\text { The university research structure capture's the main } \\
\text { components of the dissertation (2) }\end{array}$ & .956 & & \\
\hline $\begin{array}{l}\text { The academic research structure for this university } \\
\text { is well incorporated in the curriculum (6) }\end{array}$ & & .878 & \\
\hline $\begin{array}{l}\text { The academic research structure for this university } \\
\text { is simplified and not difficult to follow (4) }\end{array}$ & & .896 & \\
\hline Appendices are part of the research body (5) & & & .885 \\
\hline $\begin{array}{l}\text { Appendices include data collection tools, maps, } \\
\text { work plan, budget (1) }\end{array}$ & & .975 \\
\hline Eigen Value & 2.192 & 2.178 & 2.117 \\
\hline Variance\% & 25.797 & 23.312 & 20.211 \\
\hline Cumulative\% & 19.797 & 49.109 & 69.320 \\
\hline
\end{tabular}


Academic research coherence explained the largest part of the total variance with an Eigenvalue of 2.782 this amount to $26.586 \%$ of the total variance, and the veracity explained the second largest part of the total variance with
Eigenvalue of 2.618, this amount to $22.9 \%$, and academic research relevancy explained the lowest part of the total variance with Eigen 1.790 , this amount to $24.2 \%$ Table 3 .

Table 3. Factor Structure: Quality of Academic Research

\begin{tabular}{|c|c|c|c|}
\hline \multirow[t]{2}{*}{ Factors } & \multicolumn{3}{|c|}{ Components } \\
\hline & Coherence & Veracity & Relevant \\
\hline $\begin{array}{l}\text { A Logical flow of structure and paragraphs are observed for } \\
\text { coherence. }\end{array}$ & .961 & & \\
\hline $\begin{array}{l}\text { The university is always concerned about the homogeneity of } \\
\text { research paper. }\end{array}$ & .834 & & \\
\hline The appearance of the dissertation is always the same & .756 & & \\
\hline $\begin{array}{l}\text { Undergraduate dissertations are evaluated using the scheme for } \\
\text { consistency. }\end{array}$ & & .835 & \\
\hline $\begin{array}{l}\text { Always university make sure students get clearance before data } \\
\text { collection. }\end{array}$ & & .876 & \\
\hline $\begin{array}{l}\text { There are ethical committees in place and functioning in this } \\
\text { university }\end{array}$ & & .817 & \\
\hline $\begin{array}{l}\text { Seeking consent is perquisite for respondent to participate in } \\
\text { the study }\end{array}$ & & .581 & \\
\hline $\begin{array}{l}\text { Measures are in place in the university that evaluate originality } \\
\text { of the dissertations }\end{array}$ & & & .848 \\
\hline $\begin{array}{l}\text { Dissertations are accessed to determine reliability and validity } \\
\text { of the data collection tools for the results to be accepted }\end{array}$ & & & .914 \\
\hline $\begin{array}{l}\text { Students are guided to conduct academic research that are } \\
\text { relevant to the society. }\end{array}$ & & & .937 \\
\hline Eigen Value & 2.782 & 2.618 & 1.790 \\
\hline Variance \% & 26.586 & 22.910 & 24.190 \\
\hline Cumulative \% & 26.586 & 49.496 & 73.686 \\
\hline
\end{tabular}

\section{Discussion}

Research structure is positively correlated with quality of academic research $(r=0.698, p<$ $0.01)$. This denotes that the research procedure relates to the quality of academic research in public universities in South Sudan.

There is consistency in the general structure of the academic research. The dissertations reviewed have preliminary pages, a research body, and appendixes. This finding is almost universal no deviation is found in the literature here $[17,18,19]$.

A significant variation is seen in the contents and order of the contents under the main sections of the academic research in South Sudan Public Universities. These inconstancies are seen in different universities' guidelines such as Nairobi, MT Kenya, MakereFre, Sydney, Harvard etc. There is no consistency in the 
academic research contents and their order for students to follow and supervisors as well.

Contents under the preliminary pages section are found to be consistent in all the public universities in the Republic of South Sudan. The contents include acknowledgment, dedication, inner title page, declaration, resolution, abbreviations, table of contents, list of tables, and list of figures Figure 1. These imply that
South Sudan public universities did not contradict the traditional contents of preliminary pages from other universities [20]. Though some of the compulsory contents such as the table of contents, list of tables, and list of figures scored very low compared to some of the optional contents, such acknowledgment and dedication were among the commonest contents in the dissertations with more than $90 \%$.

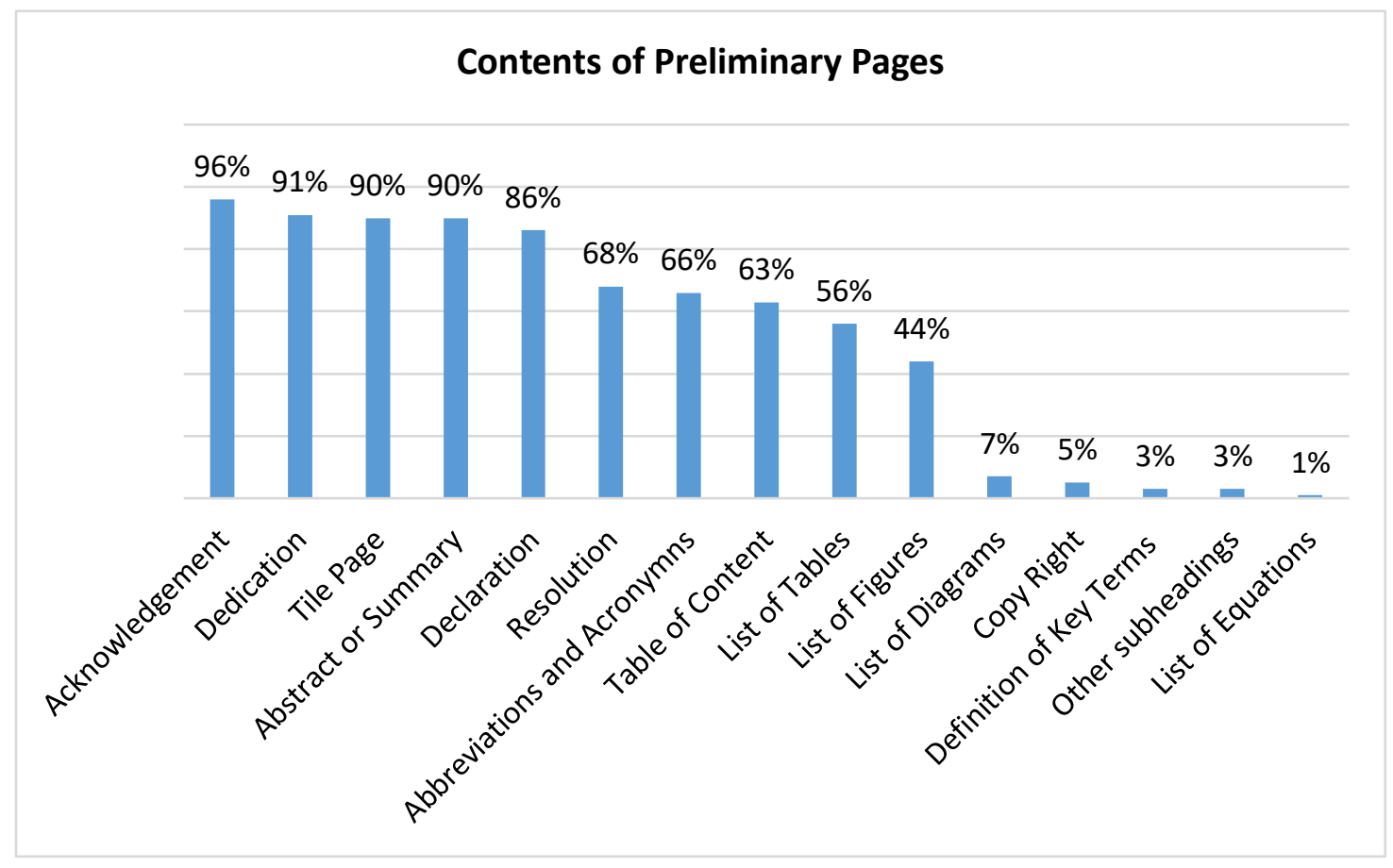

Figure 1. Preliminary Pages Contents

There is a significant variation in the order of the contents under the preliminary pages section. The inner title page is the only content that is put as the first page without page number by all students accept one percent of the dissertation from all the academic research reviewed.

The resolution or certificate page is also left without the page number after the inner title page. However, only $36 \%$ of the dissertation had a resolution page. $33 \%$ of the dissertation did not have the resolution page. The remaining portion of the review of the dissertation put it in a different order.

The second most common content under the preliminary pages section is a declaration with $69 \%$, and $14 \%$ of dissertations did not have it. This is a compulsory content of the preliminary pages section, yet some academic research did not have it at all. The rest of the contents under the preliminary pages section are less common, with $50 \%$ or below in the academic research for South Sudan public universities. The other contents are either not there or they are put in another less common order. These explained inconsistency in the order of the contents under the preliminary pages section of the academic research for South Sudan Public Universities. There is no universal order for contents under the preliminary pages section. It depends on the academic research structure put in place by the university.

This research examined the titles used for all the sections of academic research in public universities in South Sudan.

The background of the study is the least used title for chapter one, though there are some 
common titles that represent the structure. The two most frequent titles used for the first academic structure are introduction and background (38\%) and introduction alone (38\%), with less than half of the dissertations reviewed. This is another inconsistency in the academic research in the public universities of the Republic of South Sudan. A small number (14\%) of the academic research started with a literature review as chapter one. All the articles and academic research structures consulted did not put literature review as a title for chapter one $[21,22]$. The qualitative findings concurred with the literature Figure 2.

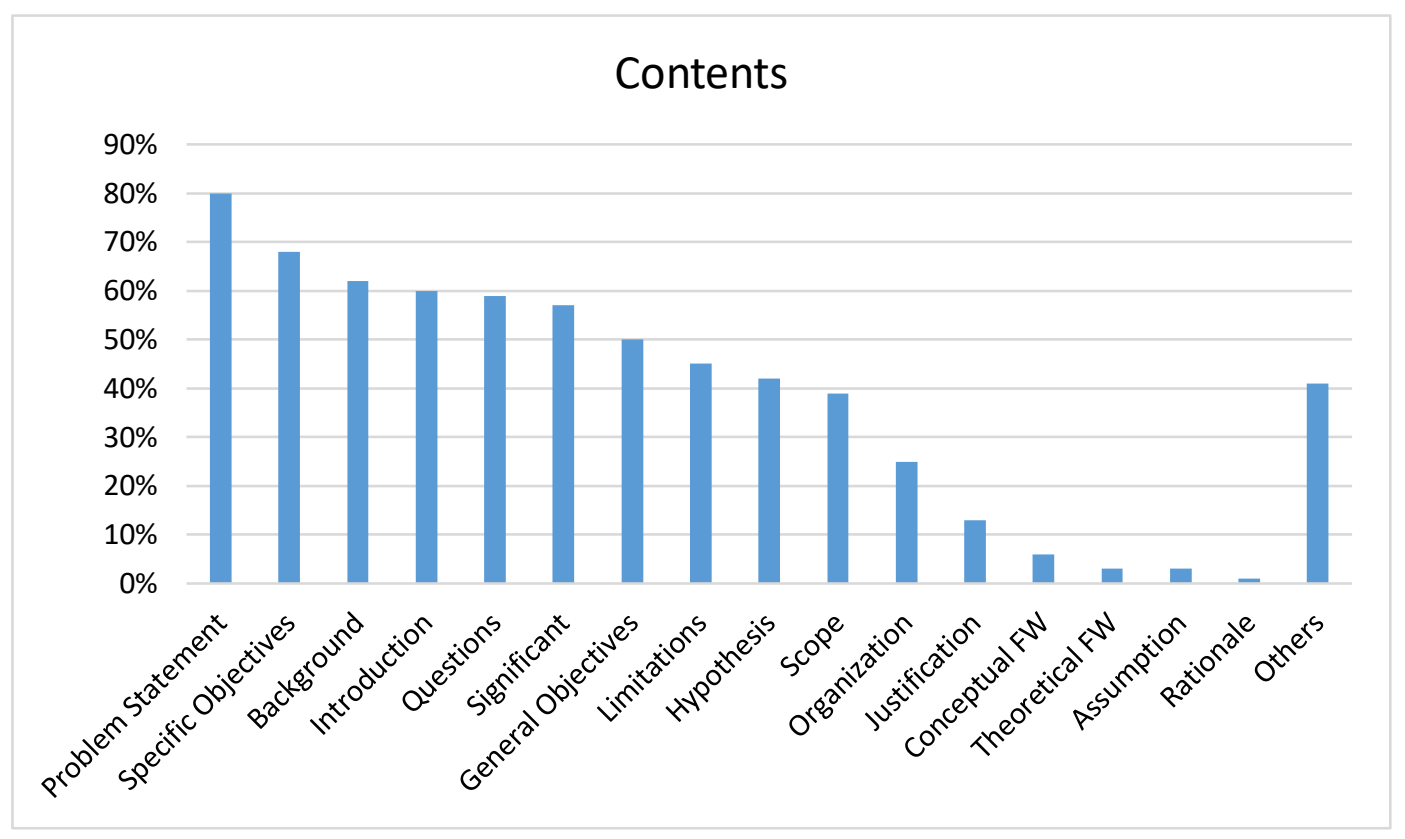

Figure 2. Availability of Common contents under Chapter One

This study is consistent with literature where second academic structure title is a literature review with a very big margin of nearly $75 \%$ of the academic research reviewed compared to the other chapters. Another $15 \%$ of the academic research used methods and materials for chapter two Figure 3. Most of the key informants interviewed did say the title for chapter two is the literature review.

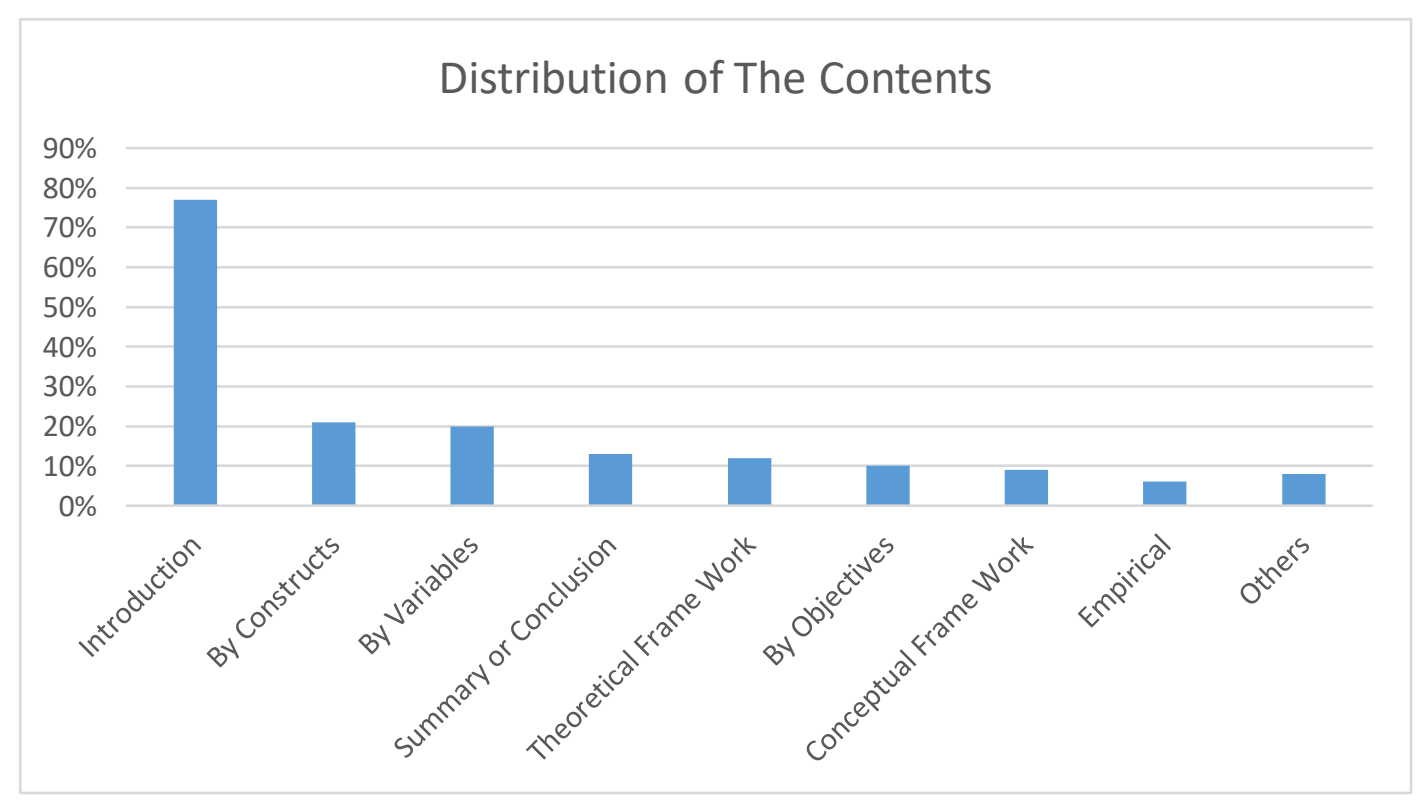

Figure 3. Distribution of Chapter Two Content 
In South Sudan public universities, there is no consistency in the title used for chapter three despite the wide range of literature recommendations for methodology or designs and methods. None of the well-known titles for chapter three were used by the students. Less than thirty percent $(28 \%)$ of the dissertation reviewed used research methodology, and this is the highest percentage. The second most common title is a methodology with only $22 \%$.
Surprisingly, $9 \%$ and $7 \%$ of the dissertations reviewed used results and research procedures as titles for chapter three, respectively. This finding is only found in South Sudan public universities. None of the respondents indicated results as a title for academic research structure, but methodology, research methodology, and materials, and methods were some of the titles mentioned during the interview Table 4.

Table 4. Material and Methods

\begin{tabular}{|l|l|l|}
\hline S/No & Title & Percent \\
\hline 1 & Research Methodology & $28 \%$ \\
\hline 2 & Methodology & $22 \%$ \\
\hline 3 & Results & $9 \%$ \\
\hline 4 & Designs and Methods & $6 \%$ \\
\hline 5 & Methods & $3 \%$ \\
\hline 6 & Procedures & $7 \%$ \\
\hline 7 & Other Titles & $21 \%$ \\
\hline
\end{tabular}

There is no clear title for academic research structure in South Sudan public universities. The result shows more than fifteen titles used in the academic research. Though some of the colleges spelled it out clearly in the academic research guidelines. There is no title being used frequently as the results show $11 \%, 10 \%$, and $9 \%$ are the most common titles used, and these are (1) Results and discussion; (2) Data
Analysis, results, and Discussion; (3) Discussion and analysis respectively. The other eleven titles, their frequency is either 5\% or less. These inconsistencies could be attributed to inadequate supervision of academic research at the higher level beyond supervisors. Secondly, there is no close monitoring of the implementation of the academic research policies and guidelines Table 5.

Table 5. Findings

\begin{tabular}{|l|l|l|}
\hline S/no & Titles Used in the Academic Research & Percent \\
\hline 1 & Results and Discussion & $11 \%$ \\
\hline 2 & Data Analysis, Results, and Discussion & $10 \%$ \\
\hline 3 & Discussion and Analysis & $9 \%$ \\
\hline 4 & Data Presentation, Analysis, and Interpretation & $5 \%$ \\
\hline 5 & Data Analysis & $3 \%$ \\
\hline 6 & Methodology & $3 \%$ \\
\hline 7 & Conclusion and Recommendations & $3 \%$ \\
\hline 8 & Data Analysis and Results & $3 \%$ \\
\hline 9 & Data Presentation, Analysis, and Discussion & $3 \%$ \\
\hline 10 & Data Anaylsis and Discussion & $3 \%$ \\
\hline 11 & Results and Interpretation & $2 \%$ \\
\hline 12 & Research Findings, Discussion and Presentation & $2 \%$ \\
\hline 13 & Presentation and Interpretation of Findings & $2 \%$ \\
\hline
\end{tabular}




\begin{tabular}{|l|l|l|}
\hline 14 & Data Analysis and Interpretation & $2 \%$ \\
\hline 15 & $\begin{array}{l}\text { Other Titles (Results and Findings. Findings, } \\
\text { Conclusion, and Recommendations. Analysis, } \\
\text { findings, and Results. Findings. Findings and } \\
\text { Discussion. And many more other titles) }\end{array}$ & \\
\hline
\end{tabular}

The study found that there are more than seven different titles used for chapter five in the academic research in South Sudan, with the most frequently (31\%) title being summary, conclusion, and recommendations compared with the other five titles since $22 \%$ of the dissertations reviewed did not have some parts Table 6.

Table 6. Discussion

\begin{tabular}{|l|l|l|}
\hline S/No & Title & Percent \\
\hline 1 & Summary, Conclusion, and Recommendations & $31 \%$ \\
\hline 2 & Chapter Five not there at all & $22 \%$ \\
\hline 3 & Conclusion and Recommendation & $21 \%$ \\
\hline 4 & Summary and Findings & $6 \%$ \\
\hline 5 & Summary and Recommendations & $5 \%$ \\
\hline 6 & Discussion & $3 \%$ \\
\hline 7 & Other Titles used & $12 \%$ \\
\hline
\end{tabular}

Literally, there is no chapter six in the academic research in the public universities of the Republic of South Sudan. The insignificant number of the dissertation reviewed had chapter six titled conclusion and recommendations.

This study evaluated and compared contents and the order of the contents under chapter one for consistency across five South Sudan Public Universities. Some of the common contents under chapter one based on the literature include an introduction, background or both, statement of the problem, study objectives, research questions, and hypothesis, or both. The other contents differ from one university to the other based on the university research guidelines. These contents include research justifications, rationale, scope, significance, conceptual framework, or theoretical framework or both, limitations, assumptions, etc. There is a significant variation between universities in the globe and the region when it comes to the contents of the academic research structure.

South Sudan universities are not exceptional, the most frequent contents under in the academic research structure in South Sudan public universities are problem statement $(80 \%)$, specific objectives (68\%), background (62\%), introduction (60\%), research questions (59\%), significant (57\%) and general objectives (50\%). This finding shows that not all dissertations reviewed had the above contents. The other contents are less frequently used in academic research Table 7.

Table 7. Structure Order of the Contents

\begin{tabular}{|l|l|l|l|l|}
\hline Content & 1st order & Percent & 2nd order & Percent \\
\hline Introduction & First & $58 \%$ & Not There & $40 \%$ \\
\hline Problem Statement & Second & $38 \%$ & Third & $34 \%$ \\
\hline Background & Second & $37 \%$ & Not there & $39 \%$ \\
\hline Specific Objectives & Fourth & $32 \%$ & Not There & $32 \%$ \\
\hline General Objectives & Third & $21 \%$ & Not there & $50 \%$ \\
\hline
\end{tabular}




\begin{tabular}{|l|l|l|l|l|}
\cline { 4 - 5 } Questions & Sixth & $21 \%$ & Not there & $41 \%$ \\
\hline Limitations & Eighth & $16 \%$ & Not there & $55 \%$ \\
\hline Hypothesis & Fifth & $16 \%$ & Not there & $58 \%$ \\
\hline Scope & Seventh & $16 \%$ & Not there & $62 \%$ \\
\hline Significant & Sixth & $15 \%$ & Not there & $43 \%$ \\
\hline Organization & Eighth & $7 \%$ & Not there & $75 \%$ \\
\hline Justification & Fourth & $3 \%$ & Not there & $86 \%$ \\
\hline Conceptual FW & Seventh & $2 \%$ & Not there & $95 \%$ \\
\hline Assumption & Tenth & $2 \%$ & Not there & $96 \%$ \\
\hline Theoretical FW & Ninth & $1 \%$ & Not there & $97 \%$ \\
\hline Rationale & Sixth & $1 \%$ & Not there & $99 \%$ \\
\hline Others & 1 st to 11 th & $40 \%$ & Not There & $60 \%$ \\
\hline
\end{tabular}

The order of the contents under chapter one has significant variations, with only the introduction emerging at the first content and only $58 \%$ of the dissertations reviewed. The order of the rest of the content did not reach $50 \%$. This implies that there is no consistency in the order of the contents. Each student and mentor decide the contents.

There is no clear guideline set forth to be followed by both students and their supervisors. These created great variations in the contents and order of the contents of chapter three of academic research structure in public universities in South Sudan.

The contents observed in the structure whether there are based on research constructs or variables, or by research objectives, theoretical framework or by conceptual framework or empirically. The study shows that $77 \%$ of the dissertations reviewed using observation check introduced the structure, and $23 \%$ of them did not.

Small fractions $(\leq 20 \%)$ of the academic research structured literature based on the study constructs, variables, theoretical framework, objectives, conceptual framework, empirical, and $13 \%$ of the dissertations had the conclusion.
There is a substantial variation in the availability of compulsory contents of the academic research structure. Only $60 \%$ of the dissertations that had introduced the chapter. Academic research designs are the most frequent (71\%) content of the academic research structure, and it is worth mentioning $29 \%$ of the dissertations did not have study designs. Target population, data collection methods, and sampling techniques are the only contents that score slightly more than average compared to the other contents with less than $50 \%$ of their availability in the academic research structure in the public universities of the Republic of South Sudan. These contents include sample size determination, data collection instruments, data analysis techniques, study areas, ethical consideration, validity and reliability of data collection tools, sources of data, inclusion, and exclusion criteria. These imply that all contents below the average are not adequately in a academic research structure in public universities of South Sudan. The contents of the structure are inconsistent with the public universities' research guidelines Table 8 .

Table 8 Structure Order of the Contents

\begin{tabular}{|l|l|l|l|l|}
\hline Content & 1st order & Percent & 2nd order & Percent \\
\hline Introduction & First & $56 \%$ & Not There & $41 \%$ \\
\hline Design & Second & $44 \%$ & Not There & $30 \%$ \\
\hline Target Population & Third & $27 \%$ & Not There & $42 \%$ \\
\hline
\end{tabular}




\begin{tabular}{|l|l|l|l|l|} 
Area of Study & Third & $15 \%$ & Not There & $68 \%$ \\
\hline Sample Size Determination & Fourth & $15 \%$ & Not There & $54 \%$ \\
\hline Data collection Instruments & Fourth & $9 \%$ & Not There & $61 \%$ \\
\hline Research Structure & Fourth & $1 \%$ & Not There & $98 \%$ \\
\hline Sampling Techniques & Fifth & $15 \%$ & Not There & $50 \%$ \\
\hline R. Procedure/Approach & Fifth & $3 \%$ & Not There & $90 \%$ \\
\hline Ethical Consideration & Fifth & $6 \%$ & Not There & $74 \%$ \\
\hline Data Analysis Techniques & Sixth & $6 \%$ & Not There & $63 \%$ \\
\hline Sources of Data & Sixth & $7 \%$ & Not There & $83 \%$ \\
\hline Inclusion and Exclusion Criteria & Sixth & $7 \%$ & Not There & $89 \%$ \\
\hline Reliability and Validity & Seventh & $5 \%$ & Not There & $80 \%$ \\
\hline Limitations & Seventh & $2 \%$ & Not There & $96 \%$ \\
\hline Data Collection Methods & Eighth & $9 \%$ & Not There & $46 \%$ \\
\hline Research Organization & Eighth & $1 \%$ & Not There & $98 \%$ \\
\hline Variables Measurements & Ninth & $3 \%$ & Not There & $91 \%$ \\
\hline Conclusion & Tenth & $2 \%$ & Not There & $96 \%$ \\
\hline
\end{tabular}

The order of the contents under chapter three is not consistent across the public universities and between the colleges with the same universities. The highest percentage of the dissertations placed introduction as first content is only $56 \%$, and $41 \%$ of the dissertations reviewed did not have introduction. Though $30 \%$ of dissertations did have research designs, $44 \%$ of them put study design as the second content after chapter three introduction. This finding is consistent with the literature in terms of their availability under chapter three and their order. The methods and materials part is introduced and followed by research designs, as seen in Harvard University's research structure. The order of the contents is presented by insignificant proportions of the dissertations, as the majority of contents are missing the academic research.

\section{Conclusion}

In conclusion, the structure of the academic research is not consistent between the five public universities in South Sudan, between the faculties and departments of the same public university. Academic research structure is positively correlated with the quality of the academic research in public universities of the Republic of South Sudan. There is consistency in the general structure of the academic research. The dissertations reviewed have preliminary pages, a research body, and appendixes. This finding is almost universal no deviation is found in the literature here. The contents and their order of the main body of the academic research structures they vary significantly in South Sudan Public Universities.

\section{Acknowledgement}

First and foremost, praises and thanks to the God, the Almighty, for His showers of blessings throughout my research work to complete the research successfully.

I would like to express my deep and sincere gratitude to my research guides, Dr. Abayomi Joseph, and Co-guide Prof. Dr. Akway M. Cham Head of Community Medicine School of the Medicine University of Juba, for giving me the opportunity to do research and providing invaluable guidance throughout this research. Their dynamism, vision, sincerity, and motivation have deeply inspired me. They have taught me the methodology to carry out the research and to present the research works as clearly as possible. It was a great privilege and honor to work and study under their guidance. I am extremely grateful for what they have offered me. I would also like to 
thank them for their friendship, empathy, and great sense of humor. I am extending my heartfelt thanks to my mentor Jesna Merly for her supports throughout my studies without her I would have not finished successfully.

I am extremely grateful to the dean of faculties, professors and lecturers from Juba, Upper Nile, John Garang, Rumbek University, and Bhar El Gazal Universities for their support during data collection at the difficulty of Covid-19 pandemic. Not for getting the Liberians of the five public universities of the republic of South Sudan for their courageous support for me to access research materials from the libraries. My Special thanks goes to

\section{Reference}

[1] Gray E. D. 2017, Doing Research in the Business World. The London School of Economics and Political science. SAGE Publishers. https://blogs.Ise.ac.uk.

[2] Sharyl J. N., Laura A. L, and Lawrence O. G. 2009, Beyond the HIPAA Privacy Rule: Enhancing Privacy, Improving Health Through Research, Editors; Committee on Health Research and the Privacy of Health Information: The HIPAA Privacy Rule; Institute of Medicine p24 -25. ISBN: 0-30912500-6, http://www.nap.edu.

[3] Center on Education Policy 2020, Students Motivation: An Overlooked Piece of School Reform. Graduate School of Education and Human Resource Development. The George Washington University. https://www.sciencedivert.com.

[4] Abhilasha S. 2019, challenges in Developing University-industry Relationship: Quantitative Evidence from Higher Education Institutions in the UAE. (P 1) Emerald Open Research Journal. https://doi.org/10.12688/emeraldopenres.12891.1.

[5] John K. A. and Alan P. J. 2008, Undergraduate Research: Importance, Benefits, and Challenges. Samford University, Birmingham, Alabama, USA. International Journal of Exercise Science. http://www.intjexersci.com. my friend Ph.D. MPH. MD. Omer Mohamed for his generosity and willingness to provide technical assistants whenever I am in need unconditionally. I would like to thank my boss Dr. Gasim CEO for access for Humanity, my friends and colleagues at AFH for their corporation and understanding in providing enabling environment at my work.

My special appreciation goes to my family for their moral support and patience during my academic journey.

\section{Conflict of Interest}

I (the Author) declare that there is no conflict of interest.

[6] UNSD, 2019 Sustainable Development Goals Report. Development Data and Outreach Branch. New York, NY 10017.

[7] John W. Creswell and J. David Creswell 2017 Research Design: Qualitative, quantitative, and mixed methods Approaches https://edge.sagepub.com/creswellrd5e.

[8] Kjell E. R. and Rae R. N. 2017, Surviving Your Dissertation: A comprehensive Guide to content and process $3^{\text {rd }}$ ed. P 90 - 94. Sage Publications, Inc. ISBN 978-4129-1678-3.

[9]Elena Vegni, Lidia Borghi and Julia Menichetti, 2020, Patient-Centered Infertility Care: Current Research and Future perspective on Psychosocial, Relational and Communication Aspects. Frontier in Psychology. Volume 12 article 72485.

[10] Patino, C. M., \& Ferreira, J. C. (2018). Inclusion and exclusion criteria in research studies: definitions and why they matter. Brazilian Journal of Pulmonology: official publication of the Brazilian Society of Pulmonology and Phthisology,44(2), 84. https://doi.org/10.1590/s1806-37562018000000088. [11] Gallup 2020, the Power of Gallup Q12 employee Engagement Survey. https://www.gallup.com/access/323333/q12employee-engagement-survey.aspx.

[12]Nilesh G. 2013, Ethical Consideration in Research. / International Journal for Research in Education Vol. 2, Issue:7. 
[13] McMaster University 2018, Academic Integrity Policies, procedures, and guidelines. https://secretariat.mcmaster.ca/app/uploads/Academi c-Integrity-Policy-1-1.

[14] Hamed T. 2016, Validity and Reliability of the Research Instrument; How to Test the Validation of a uestionnaire/Survey in a Research. University of Canada West. SSRN Electronic Journal 5(3):28-36 DOI:10.2139/ssrn.3205040.

[15] Siegmund B. 1998, Data Analysis Siegmund Brandt Statistical and Computational Methods for Scientists and Engineers $4^{\text {th }}$ ed, Department of Physics University of Siegen Siegen, Germany. Cham Heidelberg New York Dordrecht London. ISBN 978-3-319-03761-5 ISBN 978-3-319-03762-2 (eBook) DOI 10.1007/978-3-319-03762-2.

[16]Kenneth E. C. and Karen E. J. 2014, Essential of Marketing Research into Practice. SAGE Publication Inc. ISBN 978-1-4129-9130-8. P322.
[17]University of Nairobi 2010, Guidelines for Project Paper and Thesis Proposal Writing. [18] University of Technology Sydney (2017). Research Proposal Writing. ELSSA Center: UTS. Accessed on 22 March 2020.

[19]Mount Kenya University 2020, Policies, Procedures, guidelines. Approved on $11^{\text {th }}$ March 2020. https://cgsr.mku.ac.ke.

[20]Fedrick M. (2018). Step-by-step Practical Guide for Mastering Research: FEM Consultants and Research Center Limited. P 6. ISBN: 978-99709305-5-5.

[21] Onen D. 2014, How to Write a Successful Doctoral Research Proposal: The Makerere Format. EASHESD, College of Education \& External Studies, Makerere University. P 3.

[22] Rung O. K., and Scarcello M. 2016, model of the structure of nursing knowledge for research and practice. Faculty at Health Sciences and Nursing. 